\section{Was Taung human or an ape?}

Sir-Conroy and Vannier, who concluded that the Taung fossil hominid had an ape-like pattern of tooth development and emergence on the basis of computerized tomography (CT) scans', have recently stuck to their view ${ }^{2}$ in spite of evidence that demonstrates their error ${ }^{3}$. What CT really seems to show is that the Taung dentition developed according to a human pattern, but that the child may be younger than the 5-7-year old postulated on previously available evidence ${ }^{4}$. The dental developmental sequences which they claim are diagnostic of ape status in this specimen actually only separate American human juveniles from ape juveniles.

This is exemplified when non-American samples are examined, as $\mathrm{Mann}^{3}$ noted. Conroy and Vannier question ${ }^{2}$ the existence of a Taung-like human specimen ${ }^{3}$, published by Mann, although both the excavation report and associated, but unphotographed, jaw fragments demonstrate its singular identity. Although it is not the "best example" of an ape pattern in this collection, it is one in which the dentition could be easily removed for clear photographic inspection, and is only one of a number of specimens sharing this pattern. Microscopy reveals no evidence of eruption of the lower incisor teeth whereas there clearly is a recently erupted M1; therefore it is more similar to what has been published as an ape-like pattern of dental development ${ }^{5}$ than Taung. Either simple comparisions of individuals with this references is invalid or recent humans grew like apes.

Also, the second molar-canine dental sequence said to be diagnostically ape-like in Taung, and found in other fossils such as MLD (Makapansgat) 2 as well as the WT 15000 Homo erectus maxilla, is said to occur in living humans only one per cent of the time or less ${ }^{6}$. However this is a figure derived not from 'humans' but Americans. Examination of even a small sample (seven) of Near Eastern archaeological juvenile specimens with one of these two teeth just erupted, shows that the canine is earlier or simultaneous in five and the molar earlier in two.

A similar problem mars the claim that the timelag between first molar and central incisor eruption and development is diagnostically ape-like in Taung. If Taung followed a human pattern of dental development, the rootless condition of the incisors would not necessarily be unexpected for humans. The assertion that eruption of human $\mathrm{I} 1$ and $\mathrm{M} 1$ are simultaneous and, by implication, that these teeth should be in the same relative state of calcification', is a primary criterion in the claim of an ape-like pattern of dental development in Taung ${ }^{1,6}$. Yet, a survey of 20 human samples world-wide shows the range of mean incisor eruption delays behind first molar eruptions to be $0.3-1.9$ years for the maxillary teeth. Although the lag is again minimal for American samples, it exceeds 1.5 years for almost one quarter of the samples and the mean difference between incisor and molar eruptions is 1.1 years. Thus the calcification status observed in Taung does not necessitate interpretation of an ape eruption sequence, as Conroy and Vannier claim'. First molar eruption associated with a just-completed central incisor crown must be found within all human populations and must be the normal condition in many of them, based on these eruption data. These features of the Taung specimen, paralleled by a number of archaeological specimens, cannot distinguish between humans and apes. Neither Mann's data nor ours deny that apes and humans can be distinguished, only that they cannot be sorted on such a limited basis. So, neither the tooth development nor the implied emergence data reveal Taung as dentally like a 3.3-year-old ape.

Finally, we emphasize that the original primary critierion for ape-like staus was its dental development pattern'. Issues not relating to dental calcification and pattern, for example morphological features which they emphasised subsequently ${ }^{2}$, tell us what most of us knew: Taung is not a modern human. These features cannot override or deny the essentially human (if un-American) pattern of the now clarified Taung dentition.

We can conclude from the new CT data that Taung is younger than previously supposed according to a human emergence pattern. An age of about 4.5-5.5 years, at the low end of the human range of population means for first molars like Taung's, would account for the dental condition of this australopithecine child. It is an earlier age at death, rather than the reflection of an ape-like eruption pattern, that best fits the CT observation on Taung.

Milford H. WopofF
Department of Anthropology,
University of Michigan, Ann Arbor, Michigan 48109, USA

JANET M. MONGE Physical Anthropology Section,

University Museum,

Michelle Lampl

School of Medicine,

University of Pennsylvania,

Philadelphia, Pennsylvania 19104, USA

I. Conroy, G. \& Vannier, M. Nature 329. 625-627 (1987).

2. Conroy. G. \& Vannier. M. Nature 333, 808 (1988)

3. Mann. A.E. Nature 333, $123(1988)$

4. Mann. A. E. Paleodemographic Aspects of the South African Australopithecines (University of Pennsylvania. Philadel phia. 1975)

5. Dean. M.C. \& Wood. B. Folia Primatol. 36. 111 (1981).

6. Smith, B.H. \& Garn, S.M. Am. J. phys. Anthropol. 74. 289 (1987).

Bromage, T. J. hum. Evol. 16. 257-272 (1987).

\section{Ozone destruction by algae in the Arctic atmosphere}

SIR-Barrie et al. have shown' that ozone destruction occurs in the Arctic atmosphere during March and April of each year, as the Sun rises. They show that this phenomenon is linked to the photochemistry of bromoform formed biologically in the Arctic Ocean, and suggest that the production of bromoform is due to the decay of marine red benthic algae ${ }^{2}$. But it is well documented ${ }^{3}$ that temperate marine macro-algae (such as the brown seaweed Ascophyllum nodosum) produce volatile organic compounds such as bromoform in substantial amounts $\left(\sim 10^{4}\right.$ tons per year). This is of the same order of magnitude as the production by industry.

Maximal release of polybromomethanes by the two brown algae tested ( $A$. nodosum and Fucus vesiculosis) was observed in October and November ${ }^{3}$. We have recently identified a group of novel vanadiumcontaining bromoperoxidases in brown seaweeds ${ }^{4}$ that produce free hypobromous acid $(\mathrm{HOBr})$ and bromine $\left(\mathrm{Br}_{2}\right)$ in solution $^{5}$. We assume that the bromoperoxidases are involved in the biosynthesis of these volatile halogenated metabolites by bromination of an unidentified nucleophilic acceptor in the algae. Although we have not yet carried out systematic studies, the presence of these vanadium enzymes in brown seaweeds shows a seasonal variation: maximal enzymic activity is found during the winter and spring, after which a rapid decrease is observed in the summer.

I thus propose that these vanadium enzymes are responsible for the production of bromoform and other halogenated compounds, and that this enzymic activity is linked to the observed ozone destruction. It would be of great interest to determine whether algal species present in the Arctic Ocean also contain enzymes involved in the biosynthesis of these halometabolites.

Laboratory of Biochemistry,

University of Amsterdam,

PO Box 20151,

1018 TV Amsterdam,

The Netherlands

I. Barrie. L.A., Bottenheim, J.W., Schnell. R.C., Crutzen, P.J. \& Rasmussen, R.A. Nature 334, 138-140 (1988)

2. Dryssen. D. \& Fogelqvist. E. Oceanologica Acta 4, 313-317 (1981)

3. Gschwend, P.M. MacFarlane, J.K. \& Newman, K.A Science 227. 1033-1035 (1985).

4. Wever. R.. De Boer. E.. Plat. H. \& Krenn. B.E. FEBS Lett. 216, 1-3(1987)

5. De Boer, E. \& Wever, R. J. biol. Chem. 263 (in the press).

\section{Further analysis of multiexponential functions}

SIR-One year after the publication of our paper in Nature', Tang and Norris published a scientific correspondence ${ }^{2}$ concerning our work. It seems necessary 